\title{
Cálcio ionizado no soro: estimativa do intervalo de referência e condições de coleta
}

\author{
Serum ionized calcium: reference interval estimation and blood collection condictions
}

Adagmar Andriolo'; Silvia Regina Moreira²; Luciene Alves Silva²; Aluizio Barbosa de Carvalho3; José Gilberto H. Vieira ${ }^{4}$; Maria Teresa Ghiringhello ${ }^{5}$; Yara Juliano ${ }^{6}$

\begin{tabular}{|c|c|}
\hline unitermos & resumo \\
\hline $\begin{array}{l}\text { Cálcio ionizado } \\
\text { Intervalo de referência } \\
\text { Variação pré-analitica }\end{array}$ & $\begin{array}{l}\text { Introdução: A dosagem de cálcio ionizado, em nosso meio, tem se tornado freqüente em substituição à } \\
\text { de cálcio total, com vantagens, por ser a fração fisiologicamente ativa e pelo desenvolvimento de meto- } \\
\text { dologia robusta e com relação custo/benefício adequada. Seu uso implica a necessidade de definição de } \\
\text { intervalos de referência. Objetivo: Estimar o intervalo de referência para o cálcio ionizado sérico e avaliar } \\
\text { interferências do tempo de permanência do torniquete e do resfriamento da amostra. Material e método: } \\
\text { Para a estimativa do intervalo de referência, foram incluídos os resultados de } 11.320 \text { dosagens consecutivas } \\
\text { de cálcio ionizado realizadas de janeiro de } 2000 \text { a novembro de } 2002 ; \text { para avaliar o efeito da refrigeração } \\
\text { foram realizadas } 16 \text { coletas em duplicata, sendo que um dos tubos foi colocado em banho de gelo imedia- } \\
\text { tamente após a coleta e o outro foi mantido à temperatura ambiente; para avaliar o efeito do tempo de } \\
\text { garroteamento, em seis voluntários foi realizada a coleta em um dos braços imediatamente após a aplicação } \\
\text { do torniquete e, no outro braço, após } 3 \text { minutos de garroteamento. O sangue foi colhido em tubos sem } \\
\text { ar, contendo gel separador, e centrifugado em até } 30 \text { minutos após a coleta. Todas as dosagens foram } \\
\text { realizadas em até } 4 \text { horas após a centrifugação por eletrodo íon-seletivo. Resultados: Considerando-se os } \\
95 \% \text { centrais dos dados, os limites inferior e superior foram } 1,11 \text { mmol/l (intervalo de confiança de } 90 \% \text { : } \\
1,1 \text { a } 1,11 \mathrm{mmol} / \mathrm{l} \text { ) e } 1,4 \mathrm{mmol} / \mathrm{I} \text { (intervalo de confiança de } 90 \%: 1,39 \text { a 1,41mmol/l), respectivamente. } \\
\text { Não foram detectadas diferenças significativas nos resultados das amostras com e sem refrigeração e entre } \\
\text { as amostras coletadas com menos de um minuto e com três minutos de garroteamento. }\end{array}$ \\
\hline
\end{tabular}

\section{abstract}

Introduction: The ionized serum calcium determination has become frequent replacing the total calcium with advantages: it is the physiologically active fraction, and the availability of robust methodology with favorable cost/benefice ratio. The use of this methodology implies in reference interval estimation. Objective: To estimate the reference interval for serum ionized calcium, and to evaluate interferences in tourniquet time application, and interferences in sample refrigeration before analysis. Material and method: to estimate the reference interval we included the results of 11,320 consecutive calcium ionized determinations accomplished from January 2000 to November 2002; in order to evaluate the effect of sample refrigeration, 16 samples were collected in duplicate, so that one tube was placed in ice bath and the other was maintained in room temperature. To evaluate the effect of tourniquet application time, we collected blood samples from one arm of 6 normal subjects, immediately after, and from the other arm, after 3 minutes of the tourniquet application. The blood was collected in evacuated tubes with gel separator and centrifuged up to 30 minutes after collection. All determinations were performed up to 4 hours after the centrifugation by ion-selective electrode. Results: regarding to the central 95\% data distribution, the inferior and superior limits were, respectively, 1.11 (confidence interval of 90\%: 1.1 to 1.11) and 1.4mmol/I (confidence interval of 90\%: 1.39 to 1.41). No significant differences were detected between results with and without refrigeration and between samples with less than 1 and after 3 minutes of tourniquet application.

\section{key words} Ionized calcium

Reference values Pre-analytical variation

\footnotetext{
1. Professor-adiunto de Patologia Clínica da Escola Paulista de Medicina da Universidade Federal de São Paulo (EPM/Unifesp); assessor médico do Fleury - Centro de Medicina Diagnóstica.

2. Biomédica do Laboratório Central do Hospital do Rim da EPM/Unifesp.

3. Professor-afiliado da disciplina de Nefrologia da EPM/Unifesp.

4. Professor-orientador do curso de pós-graduação da disciplina de Endocrinologia da EPM/Unifesp; assessor médico do Fleury - Centro de Medicina Diagnóstica.

5. Bacharela em Física e assessora técnica do Fleury - Centro de Medicina Diagnóstica.

6. Professor-titular da disciplina de Saúde Coletiva da Faculdade de Medicina da Universidade de Santo Amaro (Unisa).

Trabalho realizado no Fleury - Centro de Medicina Diagnóstica e no Hospital do Rim da EPM/Unifesp.
} 


\section{Introdução}

O cálcio circulante permanece em equilíbrio dinâmico em várias formas, sendo que aproximadamente $45 \%$ a $50 \%$ estão na forma iônica; $40 \%$ correspondem à fração ligada às proteínas, principalmente à albumina, e os restantes $10 \%$ a $15 \%$ estão ligados a ânions de baixo peso molecular, como bicarbonato, citrato, fosfato e lactato, sendo referidos como cálcio complexado.

A proporção entre essas formas é determinada por $\mathrm{pH}$, temperatura, força iônica e concentração de outros íons, especialmente o magnésio, presentes na amostra. A forma iônica, denominada cálcio ionizado, é o componente fisiologicamente ativo, e várias funções, como contratilidade muscular, ritmo cardíaco, neurotransmissão, coagulação sangüínea e secreção de paratormônio, são estreitamente reguladas pela sua concentração sérica.

A dosagem de cálcio ionizado por eletrodo íon-seletivo está disponível há vários anos, mas apenas recentemente equipamentos suficientemente práticos, custo-efetivos e com precisão adequada foram incorporados à prática laboratorial. Os eletrodos íon-seletivos são baseados em princípios similares, sendo que as diferenças entre os equipamentos se restringem quase que exclusivamente aos sistemas de fluxo das amostras e tipos de membranas utilizadas. Soro é a amostra de escolha para a dosagem de cálcio ionizado, ainda que, em determinadas situações, como nos serviços de urgência ou no atendimento a recém-nascidos, o sangue total apresente algumas vantagens. Nesse caso, o sangue deve ser colhido com heparina. Evidentemente, os anticoagulantes que quelam o cálcio não devem ser utilizados, e mesmo a heparina, na concentração de $30 \mathrm{U} / \mathrm{ml}$, pode causar uma redução da ordem de 3\% a 5\% no cálcio ionizado. Segundo Toffaletti ${ }^{(11)}$, as dosagens realizadas em sangue total, utilizando-se heparina sódica, ou em plasma, utilizando-se heparina cálcica, oferecem melhores resultados quando em comparação com a dosagem no soro.

Os intervalos de referência habitualmente descritos em geral discriminam o tipo de amostra - se sangue total, soro ou plasma e a faixa etária - de 1 a 18 anos e maiores do que 18 anos. Os limites desses intervalos podem ser tão amplos quanto 1,3 a $1,6 \mathrm{mmol} / /$ para sangue do cordão ou tão restritos quanto 1,2 a 1,38mmol/l para indivíduos jovens, segundo Tietz ${ }^{(10)}$.

\section{Objetivos}

Os propósitos deste trabalho foram definir intervalos de referência para o cálcio ionizado sérico em indivíduos com mais de 15 anos de idade, em nosso meio, com eletrodo íon-seletivo, a partir das dosagens realizadas na rotina laboratorial e analisar eventuais interferências nos resultados finais de variações no procedimento préanalítico, como o tempo de aplicação do torniquete e a temperatura em que a amostra é mantida antes da realização da dosagem.

\section{Material e método}

\section{Casuística}

Para o estabelecimento do intervalo de referência, foram incluídos os resultados de 11.320 dosagens consecutivas de cálcio ionizado sérico realizadas no período de janeiro de 2000 a novembro de 2002. As amostras foram coletadas de indivíduos atendidos nas unidades do Fleury - Centro de Medicina Diagnóstica e no Hospital do Rim da Escola Paulista de Medicina da Universidade Federal de São Paulo (EPM/Unifesp), ambas as instituições localizadas na cidade de São Paulo. Desses indivíduos, 7.877 (69,58\%) eram do sexo feminino, com idades entre 15 e 107 anos (média = 53,2; desvio-padrão $=16,6$; mediana $=51$ anos), e 3.443 $(30,42 \%)$ do sexo masculino, com idades entre 15 e 100 anos (média $=54,7 ;$ desvio-padrão $=17,1 ;$ mediana $=$ 55 anos). Constituiu-se um subgrupo de pacientes com idades entre 15 e 18 anos, formado por 171 indivíduos, sendo $85(49,71 \%)$ do sexo feminino e $86(50,29 \%)$ do sexo masculino.

Para avaliação do efeito da refrigeração da amostra, foram realizadas 16 coletas em duplicata, sendo que um dos tubos foi colocado em banho de gelo imediatamente após a coleta e o outro foi mantido à temperatura ambiente, entre $18^{\circ}$ e $22^{\circ} \mathrm{C}$.

Para avaliar o efeito do tempo de garroteamento, foram realizadas seis coletas, seguindo o seguinte procedimento: coleta em um dos braços imediatamente após a aplicação do torniquete e coleta no outro braço após manutenção do garroteamento por 3 minutos.

\section{Amostras}

Para a determinação do intervalo de referência, as amostras de sangue foram obtidas por punção venosa, com tempo de garroteamento inferior a um minuto. $O$ sangue foi colhido em tubos sem ar contendo gel separador. As amostras foram mantidas à temperatura ambiente e centrifugadas em até 30 minutos após a coleta. Todas as dosagens foram realizadas em até quatro horas após a centrifugação. 


\section{Método}

Para as dosagens com a finalidade de estimar o intervalo de referência, foi utilizado o método de eletrodo íon-seletivo com o equipamento AVL Omni 4 (AVL Medical Division, Graz, Áustria); para as dosagens destinadas a avaliar as influências do tempo de aplicação do torniquete e da temperatura em que a amostra é mantida, foi utilizado o equipamento AVL 9180 (AVL Scientific Corporation, Geórgia, EUA), obedecendo-se integralmente aos protocolos de uso e de manutenção fornecidos pelo fabricante. As rotinas foram monitoradas pelo uso diário de dois níveis do controle Liquichek ${ }^{\mathrm{TM}}$ (Blood Gas Plus EGL Control, BioRad Laboratories Diagnostics Group, Califórnia, EUA).

\section{Tratamento estatístico}

Para a estimativa do intervalo de referência, foi aplicado o procedimento preconizado pela National Commission for Clinical Laboratory Standards (NCCLS), número C 28-A, com o programa EP Evaluator R( ${ }^{(6)}$.

Os resultados das dosagens das amostras com e sem refrigeração e das coletadas com diferentes tempos de garroteamento foram comparados pelo teste $t$ de Student e pelo coeficiente de correlação de Pearson ${ }^{(7)}$. O nível de significância foi fixado em $0,05 \%$ ou $5 \%$.

\section{Resultados}

A Tabela 1 apresenta os dados gerais obtidos com as dosagens dos controles Bio-Rad e os respectivos intervalos aceitáveis.
A análise dos resultados evidenciou que eles possuem distribuição não-gaussiana, condicionando ao uso de estatística não-paramétrica para a determinação de intervalo que incluísse os $95 \%$ centrais dos dados. Para o conjunto de todos os indivíduos testados, os limites inferior e superior foram, respectivamente, $1,11 \mathrm{mmol} / \mathrm{l}$ (intervalo de confiança de $90 \%: 1,1$ a 1,11 mmol/l) e 1,4mmol/l (intervalo de confiança de 90\%: 1,39 a 1,41 mmol/l).

Para o subgrupo dos indivíduos com idades entre 15 e 18 anos, os limites inferior e superior foram, respectivamente, $1,17 \mathrm{mmol} / /$ (intervalo de confiança de $90 \%$ : 0,83 a $1,21 \mathrm{mmol} / \mathrm{l}$ ) e $1,4 \mathrm{mmol} / \mathrm{l}$ (intervalo de confiança de $90 \%$ : $1,36$ a $1,49 \mathrm{mmol} / \mathrm{l})$.

A Tabela 2 apresenta os dados estatísticos descritivos das dosagens de cálcio ionizado utilizados para a estimativa dos intervalos de referência em cada grupo etário e separado por gênero.

A Tabela 3 apresenta os resultados das dosagens das amostras com e sem refrigeração e a Tabela 4, os resultados das amostras coletadas em cada um dos braços, com o torniquete aplicado por menos de um minuto e por três minutos, respectivamente.

\section{Discussão}

O conceito de intervalo de referência habitualmente utilizado em medicina laboratorial é baseado na distribuição dos valores obtidos pela dosagem de um determinado parâmetro em um número significativo de indivíduos representativos de uma comunidade. Como

\section{Tabela 1 Resultados das dosagens de cálcio ionizado nos controles Bio-Rad em mmol/l}

\begin{tabular}{cccccc}
\hline & $\begin{array}{c}\text { Número de } \\
\text { dosagens }\end{array}$ & Média & $\begin{array}{c}\text { Desvio- } \\
\text { padrão }\end{array}$ & $\begin{array}{c}\text { Coeficiente de } \\
\text { variação }\end{array}$ & $\begin{array}{c}\text { Intervalo } \\
\text { aceitável }\end{array}$ \\
Nível 1 & 177 & 1,415 & 0,021 & 1,5 & $1,24-1,54$ \\
Nível 2 & 140 & 1,081 & 0,013 & 1,2 & $0,99-1,19$ \\
\hline
\end{tabular}

\section{Dados estatísticos descritivos das dosagens de cálcio ionizado em cada grupo etário separado}

Tabela 2 por sexo

\begin{tabular}{lcccccc}
\hline & \multicolumn{2}{c}{ Idade (anos) } & \multicolumn{3}{c}{ Cálcio ionizado (mmol/l) } \\
& Média & Desvio-padrão & Mediana & Média & Desvio-padrão & Mediana \\
Mulheres < 19 anos & 16,7 & 1 & 17 & 1,28 & 0,08 & 1,29 \\
Homens < 19 anos & 16,5 & 1,1 & 17 & 1,28 & 0,04 & 1,27 \\
Mulheres & 53,2 & 16,6 & 51 & 1,24 & 0,08 & 1,24 \\
Homens & 54,7 & 17,1 & 55 & 1,25 & 0,07 & 1,25 \\
\hline
\end{tabular}


limites desse intervalo, em geral, são escolhidos pontos notáveis representados por percentuais da distribuição, tais como $2,5 \%$ e $97,5 \%$ ou $5 \%$ e $95 \%$, entre outros possíveis ${ }^{(3)}$. A determinação de intervalos de referência específicos para a população na qual um novo método será aplicado é procedimento altamente recomendado pelas sociedades científicas, particularmente em se tratando de substâncias endógenas que possam ter sua concentração sangüínea condicionada a fatores hormonais, dietéticos ou ambientais. Os resultados obtidos no laboratório a partir das dosagens rotineiras podem ser utilizados para o estabelecimento dos intervalos de referência ${ }^{(4)}$, desde que o tamanho da amostra seja adequado e sejam seguidas algumas regras de identificação e a exclusão de outliers.

As regras do NCCLS recomendam que um mínimo de 120 amostras distintas seja analisado no caso de a distribuição ser gaussiana e de 200 amostras para distribuições não-paramétricas, podendo, em casos específicos, ser utilizado um número menor ${ }^{(5)}$.

\begin{tabular}{|c|c|c|}
\hline \multirow{2}{*}{$\frac{\text { Tabela } 3}{\text { Amostra }}$} & \multicolumn{2}{|c|}{$\begin{array}{l}\text { Resultados das dosagens das } \\
\text { amostras coletadas com e sem } \\
\text { refrigeração em mmol/l }\end{array}$} \\
\hline & $\begin{array}{l}\text { Amostra } \\
\text { refrigerada }\end{array}$ & $\begin{array}{c}\text { Amostra } \\
\text { não-refrigerada }\end{array}$ \\
\hline 1 & 1,3 & 1,31 \\
\hline 2 & 1,29 & 1,3 \\
\hline 3 & 1,29 & 1,29 \\
\hline 4 & 1,34 & 1,34 \\
\hline 5 & 1,33 & 1,33 \\
\hline 6 & 1,36 & 1,35 \\
\hline 7 & 1,39 & 1,39 \\
\hline 8 & 1,4 & 1,38 \\
\hline 9 & 1,35 & 1,34 \\
\hline 10 & 1,35 & 1,34 \\
\hline 11 & 1,35 & 1,34 \\
\hline 12 & 1,37 & 1,37 \\
\hline 13 & 1,35 & 1,34 \\
\hline 14 & 1,34 & 1,33 \\
\hline 15 & 1,35 & 1,35 \\
\hline 16 & 1,35 & 1,34 \\
\hline Média & 1,34 & 1,34 \\
\hline Desvio-padrão & 0,03 & 0,03 \\
\hline Coef. correlação & $r=0,973$ & $r^{2}=0,948$ \\
\hline $\begin{array}{c}\text { Teste } t \text { para } \\
\text { dados pareados }\end{array}$ & $t$ calculado $=2,15$ & $p<0,05$ \\
\hline
\end{tabular}

A preocupação em se definir um intervalo de referência para cálcio ionizado próprio se justifica por ser esta metodologia relativamente nova em nosso meio e pela ausência de referências nacionais.

Os resultados obtidos nas dosagens dos controles permitem concluir que o método utilizado é preciso, considerando-se os baixos coeficientes de variação, e suficientemente exato, com resultados sempre dentro de intervalos aceitáveis em cada um dos dois níveis analisados.

A análise da distribuição dos dados obtidos entre todos os indivíduos e os obtidos no subgrupo de pacientes entre 15 e 18 anos de idade não evidenciou diferenças significativas, justificando a utilização de um único intervalo de referência.

O intervalo estimado de $1,11 \mathrm{mmol} / \mathrm{l}$ a $1,4 \mathrm{mmol} / \mathrm{l}$ possui boa correspondência com os demais intervalos referidos na literatura ${ }^{(1,9)}$, sendo que as discretas divergências podem ser decorrentes das características dos equipamentos utilizados, do tipo de amostra e/ou do protocolo de determinação.

Ainda que condições pré-analíticas como tempo de garroteamento e temperatura na qual a amostra seja mantida tenham sido referidas como causas importantes de variações nos resultados da dosagem de cálcio ionizado ${ }^{(2,8,9)}$, nossos resultados das dosagens realizadas nas amostras mantidas à temperatura ambiente e nas refrigeradas imediatamente após a coleta, assim como nas amostras coletadas imediatamente após a colocação do torniquete e nas colhidas

Resultados das amostras coletadas em cada um dos braços, com 0 torniquete aplicado por menos de um minuto e por três minutos,

Tabela 4 em mmol/l

\begin{tabular}{ccc}
\hline Amostra & Menos de 1 minuto & 3 minutos \\
\hline A & 1,33 & 1,34 \\
B & 1,36 & 1,35 \\
C & 1,32 & 1,32 \\
D & 1,32 & 1,33 \\
E & 1,3 & 1,31 \\
F & 1,38 & 1,37 \\
& & \\
Média & 1,34 & 1,34 \\
Desvio-padrão & 0,03 & 0,02 \\
Coef. correlação & $r=0,973$ & $r^{2}=0,948$ \\
Teste $t$ para & $t$ & $p<0,05$ \\
dados pareados & calculado $=0,42$ & \\
\hline
\end{tabular}


após três minutos de garroteamento, não se mostraram significativamente diferentes.

\section{Conclusões}

A determinação de intervalos de referência específicos para a população na qual um método será aplicado é altamente recomendada. Os dados obtidos permitem a utilização de um único intervalo de referência de cálcio ionizado no soro para indivíduos acima de 15 anos, de $1,11 \mathrm{mmol} / \mathrm{l}$ a $1,4 \mathrm{mmol} / \mathrm{l}$, e sugerem que a dosagem não requer cuidados excepcionais na coleta nem refrigeração da amostra na fase pré-analítica.

\section{Referências}

I. BOWERS JR., G. N.; BRASSARD, C.; SENA, S. F. Measurement of ionized calcium in serum with ion-selective eletrodes: a mature technology that can meet the daily service needs. Clin Chem, v. 32, p. 1437-47, 1986.

2. BUCKLEY, B. M.; RUSSELL, L. J. The measurement of ionized calcium in blood plasma. Ann Clin Biochem, v. 25, p. 447-65, 1988.

3. HARRIS, E. K;; BOYD, J. C. Statistical bases of reference values in laboratory medicine. New York: Marcel Dekker, 1995. p. I-6I.

4. HORN, P. S. et al. Effect of outliers and nonhealthy individuals on reference interval estimation. Clin Chem, v. 47, n. 12, p. 2137-45, 2001.

5. HORM, P. S.; PESCE, A. J.; COPELAND, B. E. A robust approach to reference interval estimation and evaluation. Clin Chem, v. 44, p. 622-31, 1998.
6. NCCLS. How to define and determine reference intervals in the clinical laboratory. Approved Guideline, v. C-28-A, n. 15, p. 4, 2001

7.SOKAL, R. R.; ROHLF, F.J. Biometry. San Francisco:W. H. Freeman and Company, 1969.776 p.

8. THODE, J. lonized calcium and cyclic AMP in plasma and urine. Scand J Clin Lab Invest, v. 50, suppl. 197, p. 13-45, 1990.

9. THODE, J. et al. Sampling and storage of blood for determination of ionized calcium. Scand I Clin Lab Invest, v. 45, p. I31-8, 1985.

10. TIETZ, N. E. (Ed.). Clinical Guide to Laboratory Tests. 3. ed. Philadelphia:W. B. Saunders, Co., 1995. 436 p.

I ।. TOFFALETTI, J. G. Ionized calcium. In: PESCE, A. J.; KAPLAN, L. A. (Eds.). Methods in clinical chemistry. St. Louis: C.V. Mosby, 1987. p. 1010-20. 